\title{
Lieber Zockerbanken retten statt Menschen heilen?
}

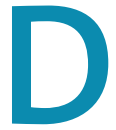

as Gesundheitswesen gehört zu den Schlüsselbranchen in Deutschland. Mehr als vier Millionen Menschen arbeiten in Arztpraxen, Krankenhäusern, Kur- und Rehakliniken, Apotheken etc. Mehr als jeder neunte Arbeitsplatz hängt hierzulande an der Gesundheit, weit mehr als in den sogenannten „Schlüsselbranchen“ Automobilindustrie, Bau oder Bankwesen. Das Gesundheitswesen war im letzten Jahrzehnt der Jobmotor überhaupt in Deutschland. Trotz immer neuer Nullrunden und rückläufiger Einkommen bei den niedergelassenen Ärzten wurden immer neue Arbeitsplätze geschaffen.

Während der Staat jetzt in der Krise jedoch handstreichartig die unvorstellbare Summe von 500.000.000.000,- Euro zur Rettung der Banken bewilligt, während Abwrackprämien und Steuersenkungen zum Wohle der Automobilindustrie beschlossen und ein immenses Investitionsprogramm für die Baubranche aufgelegt wurde, wird das Gesundheitswesen staatlich verordnet kaputt gespart. Nicht auszudenken, was eine Investition eines Bruchteils der oben genannten staatlichen Segnungen in das Gesundheitswesen an Arbeitsplätzen schaffen und an privatem Konsum fördern würde! Stattdessen versenkt ein staatlich aufdoktrinierter Gesundheitsfonds noch mehr Geld in einer überflüssig aufgeblähten Verwaltung.

Aber der Staat müsste wahrscheinlich nicht einmal wesentlich subventionieren. Immer mehr Menschen sind bereit, „Mehr als jeder neunte Arbeits- einen wachsenden Teil platz hängt an der Gesundheit, ihres Einkommens in mehr als in der Automobil- ihre Gesundheit zu invesindustrie oder im Bankwesen。“ tieren. Allein, der Staat verhindert qualitätsorientierten Wettbewerb und will stattdessen, dass alle gleich bekommen - allerdings nicht gleich viel, sondern gleich wenig. Regelleistungsvolumen begrenzen den Zugang zu qualitativ hochwertiger Medizin. Viele Kollegen überlegen, ob unter diesen Vorgaben eine allergologische Diagnostik und Therapie überhaupt noch machbar ist.

Wohin also geht der Weg im Gesundheitswesen und speziell in der Allergologie? Ein gutes Beispiel für kosteneffektive Medizin ist einmal mehr die spezifische Immuntherapie. Unabhängig von der verwendeten Applikationsform und dem

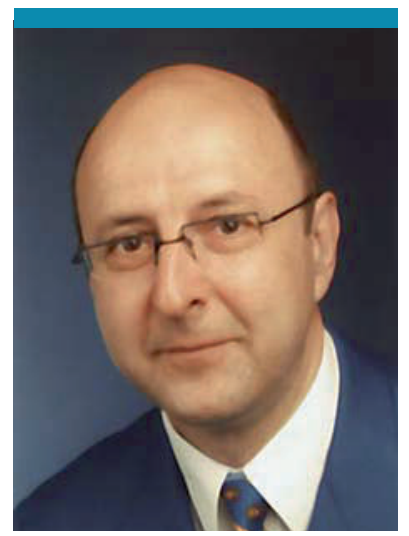

Prof. Dr. Wolfgang Czech, Präsident des Ärzteverbandes Deutscher Allergologen, VS-Villingen

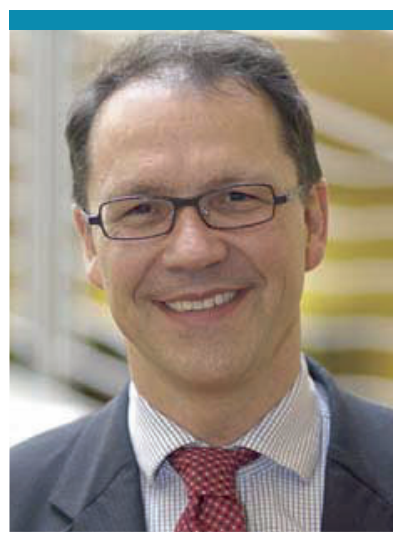

Prof. Dr. Ludger Klimek, Vorstandsmitglied des Ärzteverbandes Deutscher Allergologen, Wiesbaden gewählten Dosierschema ist die Immuntherapie medizinisch wirksam, kosteneffektiv und daher volkswirtschaftlich sinnvoll. Dennoch müssen Kollegen, die diese The-

rapie einsetzen, mit Re- „Auch Politiker sind vor Vernunft gressen seitens der Prüf- nicht dauerhaft geschützt! "“ ausschüsse rechnen. Ach

hätten wir doch lieber Milliarden in faulen Krediten und unseriösen Finanzinstrumenten verschwendet - des Staates Fürsorge wäre uns gewiss!

Wir versichern Ihnen, dass ÄDA, DGAKI und GPA in diesen Zeiten gemeinsam alles Erdenkliche versuchen werden, um die berufspolitische Situation für die Allergologen zu verbessern. Auch Politiker sind vor Vernunft nicht dauerhaft geschützt!

Glücklicherweise enthält dieses Heft auch viele erfreuliche Aspekte allergologischen Wirkens, die es trotz der politischen Nackenschläge ja weiterhin gibt. Wir wünschen Ihnen viel Spass bei der Lektüre!
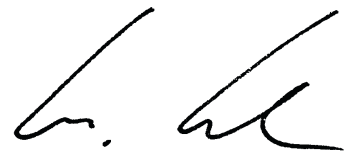

Prof. Dr. Wolfgang Czech
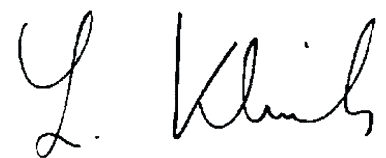

Prof. Dr. Ludger Klimek 